\title{
Early History of Sleep Research and Sleep Medicine in India
}

\author{
Velayudhan Mohan Kumar ${ }^{1} \cdot$ Hruda Nanda Mallick ${ }^{2}$
}

Published online: 13 April 2021

(c) The Author(s), under exclusive licence to Springer Nature Singapore Pte Ltd. 2021

Nowadays when one thinks of sleep medicine, the image that comes to one's mind is that of a place with a polysomnograph and several other related gadgets. William C Dement who established the world's first Sleep Disorders Clinic at Stanford University in 1970, did not have a so-called "polysomnograph", although the Stanford clinic was recording sleep and treating narcolepsy, and later insomnia, using the polygraphs. During the late 1960 's, many hospitals and labs around the world including India were recording sleep using polygraphs for treating patients with sleep disorders. In fact, the term "polysomnogram" was first coined only in 1974 by Jerome Holland to describe the measurement of multiple physiological parameters during sleep [1-4].

As in the case of the western world, the history of sleep research in India is older than the history of modern sleep medicine. Early sleep researchers paved the way for the development of sleep medicine in India. Though All India Institute of Medical Sciences (AIIMS), New Delhi was established in 1956, sleep was one of the focus areas of research of T Desiraju, BK Anand and GS Chhina of the Department of Physiology, at AIIMS, right from the 1960's [5-9]. The contributions of Desiraju on neural regulation of sleep are well recognised worldwide [10-13]. Sleep research got a boost when the International Brain Research Organization, led by DP Purpura, from Albert Einstein College of Medicine, held one of its earliest workshops at AIIMS in the late 1960s. Apart from DP Purpura, sleep scientists like Mauro Mancia from Milan, came here to work on sleep physiology on non-human primates [14, 15]. Mancia was a disciple of Giuseppe Moruzzi, the co-discoverer of Ascending Reticular Activating System.

Hruda Nanda Mallick

drhmallick@yahoo.com

1 Kerala Chapter, National Academy of Medical Sciences (India), New Delhi, India

2 Faculty of Medicine and Health Sciences, SGT University, Budhera, Gurugram, India
Another significant event was the holding of a symposium on "Consciousness" by T. Desiraju during the XXVI Congress of the International Union of Physiological Sciences in New Delhi in 1974, which had DP Purpura, M Steriade, M Mancia, NP Bekhtereva and MH Chase as some of the participants. Incidentally, Desiraju was the founder Vice President of the Indian Society for Sleep Research (ISSR). Recording of single neuronal discharge from the brain in conscious monkeys was a major contribution by him.

Sleep research in the Department of Physiology, AIIMS got a boost when Baldev Singh, the famous Neurologist, joined the department as emeritus professor in 1965 [16, 17]. Singh's interest in sleep dates back to the time when he worked in Gibb's laboratory, at the Illinois Neuropsychiatric Institute, Chicago. Gibbs and Fuster believed that sleep induced spike activity in temporal lobe epilepsy. Naturally, Baldev Singh's interest in sleep continued after his return to India. Even before joining the Department of Physiology, he participated in neurophysiological investigations on sleep and wakefulness with T Desiraju, BK Anand and GS Chhina. Sleep was recorded and analysed on the basis of EEG, EMG and EOG on patients referred to him from the departments of neurology and psychiatry at AIIMS Delhi, from the late 1960 's. He had guided many postgraduate students on sleep-related projects like electro-sleep and erectile dysfunctions.

The Indian Society for Sleep Research (ISSR) was founded on 10th September 1992 [18]. The founding ceremony was held during the "International Conference on Sleep-Wakefulness" in New Delhi on 9-11th September 1992. Owing to the initiatives of ISSR, there has been increased public awareness about sleep medicine. This has led to the growth of this field during the past few years.

The prohibitive cost of polysomnographs prevented many hospitals and labs from acquiring them [19]. Even private hospitals were hesitant, as they were not sure about the return that they will get from sleep studies done with this costly machine. Even the premier institute of the country like AIIMS got this machine much later. The first polysomnography machine was installed in the pulmonary medicine 
department in Safdarjung Hospital in New Delhi in 1995. The rapid sale of sleep machines in India occurred with the recognition of obstructive sleep apnoea syndrome as a major health issue, and non-invasive positive pressure ventilation as an accepted treatment mode. The clinical interest in sleep disorders grew rapidly in India, as the industry saw a big business opportunity in the sale of sleep recording and positive pressure ventilation machines in this country with a population of more than 130 million.

In spite of the great leaps that we have made, even in the most affluent countries, the general public is still ignorant about the importance of sleep. In this context, it very pertinent to quote from the famous book of Dement 'The Promise of Sleep'. "After all the research I have done on sleep problems over the past four decades, my most significant finding is that, 'ignorance' is the worst sleep disorder of them all. People lack the most basic information about how to manage their sleep, leading to a huge amount of unnecessary suffering. The fact is that both doctors and the general public know almost nothing about the vast store of advancement in modern sleep medicine and sleep physiology. Awareness about sleep and sleep disorders amongst doctors and the general public including our children and administrators is the need of the hour. We will not only live a healthy life but also prevent many unwanted deaths".

\section{References}

1. Mattice C, Brooks R, Lee-Chiong T. Fundamentals of sleep technology. 2nd ed. Lippincott Williams \& Wilkins; 2007.

2. Hirshkowitz M. The history of polysomnography: tool of scientific discovery. In: Chokroverty S, Billiard M, editors. Sleep medicine. New York, NY: Springer; 2015. https://doi.org/10.1007/978-14939-2089-1_13.

3. Dement WC, Vaughan C. The promise of sleep: a pioneer in sleep medicine explores the vital connection between health, happiness, and a good night's sleep. Dell Publishing Co; 1999.

4. Mallick HN, Kumar VM. Sleep medicine education in India. Sleep Biol Rhythms. 2016;14:37-44. https://doi.org/10.1007/ s41105-015-0011-0.

5. Desiraju T. Stimulus-response relationship in the production of after-discharges and their spread from intact cerebral gyri to neuronally isolated slabs. Electroencephalogr Clin Neurophysiol. 1966;21(4):345-54. https://doi.org/10.1016/0013-4694(66) 90040-x.
6. Singh B, Desiraju T, Anand BK. Electrical activity of the ventral hippocampus during sleep. Neurol India. 1966;14(3):154-6.

7. Desiraju T. Effect of intraventricularly administered prostaglandin E1 on the electrical activity of cerebral cortex and behavior in the unanesthetized monkey. Prostaglandins. 1973;3(6):859-70. https://doi.org/10.1016/0090-6980(73)90010-5.

8. Desiraju T. Neural integrations in the substrate for sleep and vigilance. Curr Mod Biol. 1971;4(1):1-11. https://doi.org/10.1016/ 0303-2647(71)90002-5.

9. Desiraju T, Anand BK, Singh B. Responses of oculomotor nucleus and marginal gyrus in sleep. Experientia. 1968;24(6):565-6. https://doi.org/10.1007/BF02153774.

10. Desiraju T. Discharge properties of neurons of the parietal association cortex during states of sleep and wakefulness in the monkey. Brain Res. 1972;47(1):69-75. https://doi.org/10.1016/00068993(72)90252-1.

11. Desiraju T. Transformations of discharges of neurons of parietal association cortex during sleep and wakefulness in monkey. J Neurophysiol. 1972;35(3):326-32. https://doi.org/10.1152/jn. 1972.35.3.326.

12. Desiraju T. Mechanisms for control of neural activity of the cerebral association cortex. II. The occurrence of recruiting type of potentials in the frontal granular cortex during stimulations of medial thalamus. Neurol India. 1973;21(4):152-8.

13. Desiraju T. Electrophysiology of the frontal granular cortex. III. The cingulate-prefrontal relation in primate. Brain Res. 1976;109(3):473-85. https://doi.org/10.1016/0006-8993(76) 90028-7 (PMID: 819103).

14. Mancia M, Desiraju T, Chhina GS. The monkey split brain-stem: effects on the sleep-wakefulness cycle. Electroencephalogr Clin Neurophysiol. 1968;24(5):409-16. https://doi.org/10.1016/00134694(68)90100-4.

15. Mancia M, Chhina GS, Desiraju T. The, "split-brain-stem" preparation in the monkey: effects on the sleep-waking cycle. Boll Soc Ital Biol Sper. 1967;43(23):1626-8.

16. Prof. Baldev Singh. President, Neurological Society of India 1962, 1971. http://neurosocietyindia.org/site/Past-president/b2/ 07\%20Prof.\%20Baldev\%20Singh.pdf. Accessed 22 Mar 2021.

17. Tandon PN. Two patriarchs of Indian Neurosciences: Professor Baldev Singh and Professor Jacob Chandy. Neurol India 2017; 65:5-10. https://www.neurologyindia.com/text.asp?2017/65/1/5/ 198174. Accessed 22 Mar 2021.

18. Kumar VM, Mallick HN, Shrivastava D. The history of Indian Society for Sleep Research (ISSR) from its inception to the launching of the journal "sleep and vigilance." Sleep Vigil. 2017;1:3-5. https://doi.org/10.1007/s41782-016-0002-5.

19. Kumar VM, Mallick HN, Shrivastava D. Demand for affordable "sleep study." Sleep Vigil. 2018;2:101-2. https://doi.org/10.1007/ s41782-018-0054-9.

Publisher's Note Springer Nature remains neutral with regard to jurisdictional claims in published maps and institutional affiliations. 